\title{
The Good, the Bad and the Ugly? The Dynamic Interplay Between Educational Practice, Policy and Research
}

\author{
PAUL VAN GEERT and HENDERIEN STEENBEEK \\ University of Groningen (Netherlands)
}

\begin{abstract}
The notion of complexity - as in "education is a complex system" - has two different meanings. On the one hand, there is the epistemic connotation, with "Complex" meaning "difficult to understand, hard to control". On the other hand, complex has a technical meaning, referring to systems composed of many interacting components, the interactions of which lead to self organization and emergence. For agents, participating in a complex system such as education, it is important that they can reduce the epistemic complexity of the system, in order to allow them to understand the system, to accomplish their goals and to evaluate the results of their activities. We argue that understanding, accomplishing and evaluation requires the creation of simplex systems, which are praxis-based forms of representing complexity. Agents participating in the complex system may have different kinds of simplex systems governing their understanding and praxis. In this article, we focus on three communities of agents in education - educators, researchers and policymakers - and discuss characteristic features of their simplex systems. In particular, we focus on the simplex system of educational researchers, and we discuss interactions - including conflicts or incompatibilities - between their simplex systems and those of educators and policymakers. By making some of the underlying features of the educational researchers' simplex systems more explicit - including the underlying notion of causality and the use of variability as a source of knowledge - we hope to contribute to clarifying some of the hidden conflicts between simplex systems of the communities participating in the complex system of education.
\end{abstract}

That education ${ }^{1}$ is a complex and dynamic phenomenon is something that hardly anyone will deny (for excellent discussions from a complexity point of view, see among others Jörg, 2011; Jörg, Davis \& Nickmans, 2007 ; Koopmans, 2014; Goldspink, 2007a, 2007b). Education is characterized by a formidable number of properties, aspects and facets that interact in all

\footnotetext{
${ }^{1}$ In this article, we shall confine ourselves to education in the more formal sense, namely related to the process of teaching and learning in school contexts. The general principles discussed in this article also apply to education in the broad sense, including education in families and child rearing.
} 
sorts of ways in order to facilitate - or hamper - the teaching-learning process. In this article, we aim to present a general perspective on the complexity of the educational process inspired by about 25 years of work in dynamic systems of development (Van Geert, 1991, 1994) and work on the complex dynamics of education (e.g., Steenbeek, Jansen, \& van Geert, 2012; Steenbeek \& Van Geert, 2013). We start with describing the concept 'complexity' by focusing on the distinction between epistemic complexity and system complexity. We introduce and describe the notion of a simplex system in order to describe how participants in an epistemically complex system such as education is, manage to understand the system and accomplish important things from their own perspective. We define such a simplex system as a connected whole of beliefs, representations, values, emotions, habits, practices and material tools that serves as a simplifying representation of the overarching complex system in which a person participates and that organizes the participants' actions. We claim that such simplex systems are characterized by system complexity which has implications for attempts to change them, e.g., by means of teacher professionalization, school reform, the improvement of students' work habits etc.

We will argue that 'agency', 'understanding' and 'accomplishing' are important and dynamic notions for those who participate in education, and we will use agent-based theorizing and modeling to underpin this argument. We will focus on the community of educational researchers as specific agents in the complex system of education, in relation to the communities of educators and educational policy makers (thus leaving aside the communities of those who are being educated, such as children or students 2 ). We then proceed with a discussion on how researchers try to accomplish their particular scientific concerns and goals by focusing on information about two types of variability in educational data, namely intra- and inter-individual variability, and on how the researcher's choice for one type of variability as a basic source of knowledge about the educational system has consequences for the kind of results the research produces. We shall focus on potential tensions between the communities in education and on the role that simplex systems play in the activities that are typical of each community (e.g. teaching, doing researcher, making policy decisions).

\section{Two meanings for the concept of complexity}

The concept of complexity is not unanimously defined, but two different kinds of meaning stand out in the informal, scientific and policy discourse regarding complexity, and this is also clearly so in the field of education.

\section{Complexity meaning "hard to understand, difficult to manage..."}

One possible meaning of complexity is "hard to understand", "complicated', 'intricate', which actually implies "hard to simplify". That is, if we have some sort of phenomenon or problem that is characterized by a myriad of properties, each of which is about as important as any other, we typically have a complex phenomenon or problem. The basic question for anyone involved in this particular phenomenon or problem, is always how to make this form

\footnotetext{
${ }^{2}$ The distinction between educators and those being educated is somewhat artificial, and the two aspects are often intertwined. Teachers for instance are educators, but as they are in the process of lifelong learning, they are also being educated, finding themselves in the school benches, sitting opposite to an instructor.
} 
of complexity tractable and understandable. Given the limits of human cognitive understanding, this is a question that always amounts to the question of how complexity can be simplified.

Education is complex in the sense that it involves many different organizational levels: it starts with the interaction between a (group of) child(-ren) (or student(s)) and a teacher, and it goes all the way up to the level of political policymaking about education and the level of the economic organization that is necessary to allow a country to organize its educational system efficiently and effectively (this form of nested complexity is explicitly described in models such as that of Bronfenbrenner and Morris, 2006, for instance).

It involves processes on the short-term timescale, for instance teacher-student interactions in the class and processes on the long-term timescale of historical changes in scholarly education. It involves millions of people being involved in educational activities. It is related to what people actually do if they are educating or being educated, to the spaces they organize for that purpose, and the material artifacts they produce to make education physically possible. For this extremely complex whole to be cognitively and physically manageable by its participants - such as educators, researchers or policymakers - those participants will need to simplify it. That is to say, they will need to create "simplexity", in the form of a simplex structure that allows them to understand the complex reality they participate in, to specify particular goals and concerns, and to accomplish things in accordance with those goals and concerns (also recall the definition given on the first page of the article). We shall see that these simplex structures differ between the communities of participants in education.

This particular notion of complexity, meaning "hard to understand, difficult to manage...", is what we shall call epistemic complexity. The idea of epistemic complexity is about as old as mankind itself, and lies at the roots of science, which is humankind's way of turning complexity into "simplicity". Instead of "simplicity", we opt for the term simplexity, which we define as 'the structure of connections between all sorts of simplifications that allow us to comprehend (which literally means "to grasp as a whole") what is basically epistemically complex' (Berthoz, 2012; Kluger, 2008). This simplexity covers various sorts of aspects, relating to 'knowing' things, 'evaluating' things and 'doing' things. That is, it might take the form of a whole of ideas, representations and cognitions about education, thus relating to what we call "knowledge". In the case of educational science, this aspect might cover the theories about learning, engagement and motivation. Second, it covers aspects of values, interests and concerns, thus relating to "evaluation". Finally, it may take the form of a set of practices, ways of doing, setting goals and accomplishing things, for instance the educational and pedagogical practices of teachers, school boards or governments. In reality, the simplex structure will consist of an intertwining of all these aspects, leading to what might be loosely called a praxis. We shall define praxis as a relatively coherent whole of practices, activities representations, justifications, evaluations, etc. that characterize a particular community of practitioners.

\section{Complexity meaning "a complex dynamic system and its associated properties"}

Another meaning of complexity, which is historically speaking relatively new, is one that refers to something that consists of many components that interact with one another, and that, because of these interactions, spontaneously produce new properties that cannot be reduced to a sum of the properties or behaviors of its components (e.g., Davis \& Sumara, 
2006; Guastello \& Gregson, 2011; Van Geert, 2008;). This notion of complexity is closely associated with the notions of dynamics and of systems, the system being defined as a set of components being related to one another, and dynamics being defined as the way in which one state of a system changes into another state over the course of time (Weisstein, 1999), This notion of complexity is associated with the notions of self-organization and emergence. Self-organization implies that the interactions between the components of the system lead to self-sustaining structures or patterns. Emergence implies that in a complex system the interactions between the components spontaneously produce new phenomena. For instance, the activities of asking questions and obtaining answers that take place among a teacher and students bring about consensual frames (Fogel, 1991), i.e., patterns of interactions that we call "a lesson", "a discussion", "a demonstration" and so forth. A particular way of reacting to one another may lead to a self-sustaining pattern in which a teacher is almost always taking the lead and the students are almost always following (for a discussion in the context of special education, see Steenbeek, Jansen \& Van Geert, 2012; Steenbeek \& Van Geert, 2013). In this sense, complexity refers to everything that can be considered a complex dynamic system, consisting of interacting components, producing and maintaining emergent properties.

Interestingly enough, this second perspective on complexity has important connections with epistemic complexity, and, more particularly, with the notion of simplexity. First, this dynamic system oriented perspective on complexity provides an important tool to arrive at simplexity, that is, to arrive at a coherent and dynamic understanding of what is epistemically complex. For instance, it provides a model or theory of the process of education, but also leads to a different kind of practice (for an application in the context of developmental psychopathology, see Mascolo, Fischer, Van Geert \& Steenbeek, to appear). Second, it provides a model of simplexity, i.e., of simplex systems, e.g. those of educators, educational researchers and policy makers. Such systems consist of components (representations, narratives, values, practices, tools, etc.), that are dynamically connected to one another. These dynamic connections lead to self-organization and emergence of such simplex systems, such as scientific theories of education, or policy models such as the accountability model (Goldspink, 2007a, 2007b).

\section{Simplex systems for understanding, evaluating and accomplishing}

\section{Simplex systems and the property of control}

Simplex systems are ways of getting or having control (in the general sense of that term), either the cognitive control of understanding, the emotional control of assigning values to things and phenomena, or the control of manipulating and dealing with practical things (the term control is used in the somewhat lose meaning of having things made manageable, understandable, etc.).

Being scientists, educational scientists in this particular case, our primary aim is to explain the world as we observe it. For instance, as educational scientists we might be interested in explaining the achievement gap between students from different socioeconomic statuses, or in explaining why some educational practices provide better results than other. However, in the context of education, scientific explanation is related to a more important notion, the general notion of control, which is cognitive, emotional as well as material. To have control over things means that we can understand those things (i.e., that we have the 
feeling that we understand them, which says nothing about the truth of such understanding), that we can assign particular values to such things (e.g., determine what we find crucial, important, not important...) and that we can act to change those things in ways that comply with our interests, goals or concerns. In line with the aspects covered in simplex systems, we shall define control as something that can be achieved through understanding, evaluation (value assignment) and finally accomplishing, or accomplishment. Take for instance an educator such as a primary school teacher, and the control she has. What this teacher wants to accomplish is to act in such ways that her students indeed learn the things that she intends to teach. The teacher wants to understand what happens with her students, in relation to what he or she is doing. This understanding will probably take the form of a narrative, or narratives, ranging from written reports about problem students to explanations given to a student's parents during a teacher-parent meeting. These narratives will reflect a universe of values, norms and preferences, e.g. as to differences in "talent", "excellence", etc. The teacher wants the educational process to occur in an effective way, with assets that are emotionally, cognitively and motivationally satisfying ${ }^{3}$. For the teacher, the primary perspective is that of practical accomplishment, ranging from the short-term control needed within the confinements of a particular lesson to the accomplishment of longterm successes regarding the students' and the teacher's scholarly and professional careers. However, it is a practical accomplishment that is evaluated against a range of representations and values, e.g., the teacher's ideas about what constitutes good education, what to expect from boys and girls, and how students should behave in class. These representations and values are to a great extent implicit and situated, that is to say, co-determined by the actual context in which they function.

The notions of understanding, value assignment and accomplishment - which represent various forms of control in the general sense - directly relate to the concept of agency, and so to the dynamics of agent systems, which form, among others the subject of agent modeling, aimed at explaining the complexity of agent systems.

\section{Simplex systems and the property of agency}

The second connection to complexity goes via agency. The notion of agency forms a foundational concept for all theories of human behavior and action (see Steenbeek \& Van Geert, 2009, in the context of children's play, and Steenbeek \& Van Geert, 2013 in the general context of education; the agent model discussed in this section is based on these articles). An agent - such as a student, a teacher, a parent, a policy maker - specifically acts with the aim to realize his concerns, interests or goals. These concerns range from something so basic as the agent's physiological needs to the agent's specific representation of his psychosocial and educational goals, such as his goal to teach children how to read, or his goal to educate responsive citizens. Agents constantly evaluate the extent to which their actions realize their concerns or accomplish their goals, in a process called appraisal, and their actions are basically driven by the ever-changing distance between their concerns or goals and the way these are realized here-and-now. In the educational system, the realization of major concerns or the accomplishment of major goals of the relevant agents is critically dependent on the actions of other agents, such as the students, the parents or the school administration. For instance, if the teacher has the intention to teach his students to read, the accomplishment of

\footnotetext{
${ }^{3}$ Let us not forget financial satisfaction: a teacher wants to make a decent living from the difficult job he or she is doing, and salary can be a tool in the hands of a policy maker for instance.
} 
that goal depends on the changes in the reading activity of the students. If regional policymakers want to change the educational practices of the primary schools under their jurisdiction, the accomplishment of that goal depends on the way in which the schools and teachers incorporate the new practices and the resulting allegiance with respect to those new practices. To realize their concerns or accomplish their goals, agents, such as teachers, use various kinds of tools, such as pedagogical skills or digital school boards. They use those tools with a certain degree of competence, which is directly expressed in the ease with which they manage to achieve their concerns or goals. Since the realization of concerns or goals depends on changes in other agents, such as students, agents such as teachers must have a particular and variable amount of social power over those other agents, which allows them to reach their concerns and goals more or less efficiently. Agents depend on one another for the accomplishment of their goals, the improvement of their tools and competences, and the consolidation of their power, and by doing so constitute dynamical and complex agent systems, self-organizing into typical patterns of educational understanding, evaluation and accomplishment (Steenbeek \& Van Geert, 2013). These patterns are systems of co-dependent properties, and attempting to change one property is very likely to have an effect on other properties and on the attempt to change (Frenken, 2006). Examples of such attempts are an educator's attempt to change the study habits of a student, or a student's attempt to make the teacher explain how a particular task should be accomplished, or a policy maker's attempt to change particular educational activities of teachers. These examples introduce the theme of the next section, which is that of communities of agents in education.

\section{Educational simplex system as a complex dynamic system in itself}

Simplex systems, used by various sorts of practitioners in education, are complex dynamic systems in themselves. That is to say, the components of simplex systems, such as beliefs, pedagogical content knowledge, and pedagogical and didactic practices interact with one another, and through these interactions self-organize into systems of dynamic as well as selfsustaining ideas, practices, evaluations, motivations and so forth. That is, these simplex systems themselves behave as embedded complex systems, in the sense of sets of interacting components leading to self-organization and emergence. They are embedded in the complex system that they intend to simplify for the various participants in the system, such as educators, educational scientists and policy makers. The nature of the components and the way these components and interactions are organized will be different for different groups of participants in the complex educational system. That is to say, the self-organizing structure of practices, evaluations and representations of a teacher will differ in characteristic ways from the self-organizing structure of practices, evaluations and representations of an educational scientist, or those of an educational policy maker. However, since all these parties are involved in the complex system of education, they are connected to one another in a variety of ways. In fact, they constitute the components whose interactions lead to the self-organizational and emergent properties of the educational system as a whole.

\section{Communities of agents in education}

For the current discussion, it is important to distinguish various kinds of communities, the interactions of which constitute the complex systems of education that are typical of modern, post-industrial societies. The major community in the educational system is formed by the agents who are educated, i.e., the children or the students. However, we shall confine 
ourselves to the communities of agents who educate, either directly via teaching or indirectly via educational policymaking and scientific educational research.

We shall start close to (our) home, and begin with the community of the scientific researchers. Their goal is to find scientific explanations for the phenomena they find typical of education as a natural and cultural kind. They will want to present such explanations in the form of coherent theories, and to base such explanations on shared practices of formulating questions, doing research, and communicating the results to their peers in the form of scientific articles. Since theirs is to a great extent an applied science, they will want to apply their scientific findings and insights to make education more effective, to help educators assess the effectiveness of what they are doing and so forth (note that the chosen terminology of effectiveness is not meant to be universal; rather, it is a reflection of major but not unique perspectives on what needs to be accomplished by the educational research community). The "fundamental" as well as "applied" intentions will be governed by the simplex structure of representations and practices that is typical of their community and that helps them to achieve understanding and accomplishment in the complex system of education.

Secondly, there is the community of political (national, federal, regional...) policy makers, driven by the goal to make a nation's or a region's or a city's formal educational system successful from the point of view of political goals and values, and national and international comparisons of school performance, based on a characteristic range of standardized assessments, and of economic productivity in the form of the production of generations of professionals capable of contributing to the nation's gross national product.

Finally, there is the community without which the first and second community would have no right of existence, namely the community of educators, which, for the sake of the present discussion, we have confined to the community of professional educators, i.e., teachers in schools. Their goal is to accomplish the education of concrete individual children and students, and the growth of their competences and skills, on the short-term timescale of real teaching and interaction in classes and on the long-term timescale of guiding students through a particular school career. They will do so in light of what they perceive as moral, religious and educational standards, the requirements of a particular curriculum or the formal educational goals of a particular region, nation, religion or political system ${ }^{4}$.

The communities are characterized by the particular simplex systems they use, consisting of specific goals, interests and concerns, and by the specific practices and tools by which they try to reach these goals. They have their characteristic lines and methods of communicating their activities, views and perceived results to their peers within their community, and to members of other communities. The components of the simplex systems are interrelated in particular ways, thus creating their own characteristic dynamic systems' complexity, providing particular affordances but also setting particular constraints on processes of innovation (Frenken, 2006). Simplex systems used by the agents in a particular community share a certain number of properties (e.g. the use of statistical associations as operationalizations of relationships between variables by educational scientists), and these

\footnotetext{
${ }^{4}$ Note the interesting distinction between the perspective on individuals versus groups between educators on the one hand, and policy makers - and in most cases also educational scientists - on the other hand. We shall discuss this issue further.
} 
common properties in fact define them as members of that community. However, among the members of a particular community, there nevertheless exists a considerable variability in the beliefs and practices in what and how they wish to understand and accomplish and so forth. This variability creates its own dynamics within particular communities, the discussion of which goes beyond the scope of the current article.

\section{Scientific researchers' simplex systems and the relation with simplex systems of other communities in education}

Scientific researchers rely on particular practices of asking and formulating educational questions, on the definition of what counts as relevant data, on shared methods for data collection and processing, and on highly formalized ways of communicating the results of scientific research to their peers. For instance, a considerable majority of educational scientists will be interested in "explaining the variance" in a particular educational variable, such as school performance or success, in the form of a statistical association with another variable, the often denote by notions such as "dependent variables". This might be a variable they cannot literally control, such as socioeconomic status of the students, or it might be a variable they perceive as controllable, such as a particular type of pedagogical praxis or a particular curriculum they wish to introduce as an intervention, the effect of which they intend to study. The point is not whether or not this way of formulating the questions that are relevant for education is "the right one", or "the scientifically correct one." What we wish to illustrate here is that this way of articulating the questions is rather typical of a considerable majority of educational scientists (probably with a minority of educational scientists actually criticizing this particular practice, for instance many readers interested in the articles appearing in the journal Complicity).

As educational researchers are usually very well aware of the necessity to communicate with the communities of educators and the communities of policy makers, they try to establish particular lines of collaboration and communication with those other communities. A way to establish the link with the level of political policymaking is by applying for research money, which in many countries is now increasingly linked with and (indirectly) determined by political agendas and the goals of policy makers ${ }^{5}$. This kind of relationship between the community of educational scientists and the community of policy makers is no doubt a very subtle one, and most likely of a rather complex reciprocal nature. Political agendas and policy goals are often based on conceptualizations and models - that is, of particular simplex structures - that have originated in the community of the scientific researchers, and that, through several transformations, have found their way to the simplex structures characteristic of the policy makers. For instance, the current political wish to improve education for the excellent students, which is high on the political agenda in many post-industrialized nations, is often based on psychological and statistical theories of excellence that typically originate from the behavioral sciences. The views that politicians hold about excellence need not be the most scientifically advanced ones, and may reflect scientific mainstream ideas or even seriously lag behind modern scientific developments. For instance, in our opinion, the view of the political policy makers in the Netherlands on

\footnotetext{
${ }^{5}$ The first author, who has been involved in developmental and educational research for a little more than four decades by now, has the strong belief that political agendas on educational research become more prominent as the research finances become less affluent.
} 
excellence is rather outdated, intelligence-oriented and based on a simplistic statistical model of the distribution of excellence. Nevertheless, it is part of a political simplex system that typically originates from the thinking of the behavioral and educational sciences (maybe of a couple of decades ago).

As to the teachers, they might have an idea about psychological tests as absolutely reliable objective indicators of the true abilities of a particular child, an idea that originates in the work of behavioral and educational scientists designing tests, but that not necessarily complies with recent scientific insights in intra-individual variability in performance, for instance (Van Dijk \& Van Geert,to appear; Van Geert \& Van Dijk, 2002). Some teachers however might have a view on tests that is more similar to that of scientists who are aware of the intrinsic intra-individual variability of all performance. It is likely that their ideas are not inspired by what they know about scientific research on human abilities, since such research typically tends to emphasize the idea of "true scores". In that sense, teachers doubting the validity of standardized testing and educational assessment are likely to be set aside as being scientifically naïve. However, our research shows that their position may be less naïve than that of teachers or educational scientists for that matter, who believe in tests as measures of children's true scores on identifiable underlying abilities (Steenbeek \& Van Geert, forthcoming).

In practice, the communication between the communities involved in education often suffers from serious delays and misunderstanding of the respective goals and means to achieve them. That is to say, a scientific researcher of education must operate in a complex and dynamic structure of goals, practices, tools, incentives, institutions, political programs and material structures divided across various sorts of communities. Being distributed across those communities, the simplex systems used may sometimes conflict with one another, e.g., as regards particular goals or incentives. However, one thing that really stands out from all this complexity is that educational science, now and in the past, has played a crucial role in helping define the properties of the simplex systems that determines the praxis in the communities of educators and policymakers, as we have seen in the examples given above. Educational and behavioral scientists have to a considerable extent determined the dimensions defining the goals of education, ranging from "variables" such as intelligence to language proficiency, from conceptualizations of what counts as good reading and writing and students' understanding of science and math, from the important functions of working memory and executive functions to the notion of self-regulation, and many other variables that are now at the heart of many political and applied agendas for education. Educational and behavioral scientists have also to a very considerable extent determined the way in which these abilities and proficiencies should be assessed and measured, and by doing so have thus played a considerable role in defining what these abilities and proficiencies are. Educational and behavioral research has led to defining important educational goals as abilities that can be measured by means of standardized tests administered to individual children, focusing on subjects such as reading and writing and math. A test is in fact a highly specific, standardized, individual way of observing a set of isolated pieces of performance (the test items) under time pressure. That is to say, the way governments tend to assess the school performance of students is to a very high extent determined by the typical practices of a century of behavioral and educational research. It is even so that the way these abilities are tested has a direct effect on the way these abilities are taught. For instance, in countries that employ nationwide tests, to measure the school performance of children, such as the Netherlands, there exists a tendency to accommodate the teaching of knowledge and abilities 
in such a way that it matches the way in which this knowledge and abilities is measured (Koretz, 2008). The reason for this adaptation is that the results of these tests can have important consequences for the way schools are officially evaluated or even financed.

\section{Tensions within communities and the effect on the relation with other communities}

\section{The impact of innovations}

Educational practitioners are, among others, driven by the concern to reconcile their professional duties - including the requirement of ongoing, lifelong professionalization with their personal lives, creating potential tensions between professional requirements regarding time and effort investment on the one hand and the requirements of time and effort investment in their personal life spheres (there exist of course very similar concerns in the communities of educational researchers and policymakers).

A typical example of a potential tension between the simplex systems of researchers and those of educational practitioners is that of an educational researcher who has found that a particular pedagogical intervention, to be carried out by a teacher, is more effective than "care-as-usual". Such a finding is almost always based on statistical significances of differences in the average performance of a "treated" versus "untreated" group, which is very often a matter of differences expressed in decimal standard deviations (for instance the classical Cohen's d-measure). An educational policymaker, having learned about these results, may then impose this "evidence-based" practice on the schools under his or her governance, confronting the teachers to actually change the daily practices they are used to. This change will involve efforts, which may come above the daily efforts and chores the teacher is confronted with, sometimes leading to a considerable additional workload, that the teacher does not necessarily sees translated into major progress in his students (a statistically significant improvement of 0.25 standard deviation is not the same thing as an improvement that is clearly observable for teachers functioning in the here-and-now of their daily practice).

Let us go back to our example of a scientific finding that a particular pedagogical practice, e.g., one relating to praise or correct particular actions of students, is more effective than the way students are habitually praised or corrected (always given a particular criterion of "effectiveness"). This practice is but one component in the structure of practices, beliefs etc. that constitutes a teacher's simplex system. The point is that, like in all innovations, changing one component of a particular simplex system such as an educational praxis, has effects on other components, and tends to spread through this simplex system in various, often unpredicted ways. For instance, if an innovation involves changing a particular form of pedagogical practice by another, the change might spread towards other aspects of the educators' praxis and simplex system (see for instance Goldspink, 2007a, 2007b, for examples).

If innovation would indeed amount to the simple replacement of a particular component by another one, leading to immediate effects clearly observable for the educational practitioner - e.g., replacing one pedagogical/didactic practice by another - efforts required for such innovations could be relatively simply predicted and accounted for. However, as educational praxis forms a system of interconnected components, educational innovations may create unexpected tensions between goals, tools, evaluations, practices and required 
efforts. Such tensions, which are hard to understand from a linear, component -oriented approach on educational effectiveness, might also have an effect on social and emotional relationships with colleagues and superiors. In summary, there exists a tension between the researcher's view on a component of a pedagogical praxis that a researcher can treat as a variable that can be isolated from other aspects of the praxis, and the educator's simplex system of practices, beliefs, values, tools and so forth that tends to form a dynamic whole, in which changes in one component tend to affect changes in others.

Let us now look at the same phenomenon - a particular intervention such as a professionalization courses or the introduction of a new curriculum - from the point of view of the educational practitioner, the teacher, and in particular from the point of view of the activities of control, achievement and associated representations of causality that the teacher will experience. For the teacher, the intervention is a complex process unfolding over the course of many weeks, or longer. The teacher may feel uncertain in the beginning, resulting in an increase of helplessness, or the feeling of conflicts between the new requirements and the old, functional habits of teaching. The teacher may develop an emotional resistance to the new activities prescribed by the educational intervention, and undergo a process of splitting his or her pedagogical practices, one line of practice intended for those who want him or her to act according to the intervention scheme, and one line of practice for the teacher himself, following the practices that have been shown to be doable and sufficiently rewarding under the daily context. This would be an example of a scenario in which the intervention events are incorporated in a process that is basically a negative spiral.

However, as the process of the intervention events is embedded in a complex system ${ }^{6}$ of interacting components, values, actions, representations and so forth, it might also lead to a positive scenario: The teacher might use the intervention as an opportunity to change his or her pedagogical practice in ways that he or she finds much more appropriate, or a better match of his or her professional identity. That is to say, on the level of the actual processes, the teacher "undergoing" the intervention is in fact immersed in a complex, iterative process of reciprocal and sometimes highly unexpected influences and interactions, leading to changes that are stable or not, or results that are in accordance or not in accordance with the intentions of the intervention. What the teacher is experiencing is a process that has a particular duration, consists of iterative steps (e.g. a sequence of meetings with a coach, in the context of an intervention study) and that is in fact highly variable over time (Wetzels, Steenbeek \& Van Geert, submitted). That is, for the participating teacher, the process is anything but a simple cause-effect sequence, in contrast with the researcher's representation of that process in the form of a pretest-intervention posttest sequence, assuming some sort of direct causal influence.

What we see here is a typical incompatibility or conflict of causal models, or causal simplexes. The simplex structure that the researcher imposes on the process of the intervention can be very much at odds with the simplex structure that the educational practitioner experiences and imposes on the process in which he or she is embedded.

\footnotetext{
${ }^{6}$ We are referring to the real complex system of education in which the simplex systems and activities of the communities are embedded; as stated earlier, the simplex systems used by these communities are simplifications of the real complex systems, governing the participants' representations, values and accomplishments.
} 


\section{Intra- and inter-individual differences as sources of variability}

The incompatibility between simplex systems of researchers and practitioners, introduced in the preceding section, is at least partly based on the way these simplex structures emerge. Recall that, epistemic complexity requires the construction of some sort of simplex structure that allows an agent to act in epistemically complex systems, such as education. For the educational researcher, reduction towards more simplicity can be acquired by looking at covariation or coherence: if a property co-varies with another property, which covaries with yet another one, those properties can be reduced to a single underlying property, which in the jargon, is often called a latent variable. In the sciences of education, as in the behavioral sciences in general, there are two very important sources of variation, i.e., very important sources of differences.

One source concerns the differences between people, the other source concerns differences within people. Which source is actually used has far-reaching consequences for the nature of understanding, evaluation and accomplishment in education, and may lead to various sorts of (subtle) misunderstanding between the communities in the educational system. Differences between people can be studied by comparing individuals, collected in the form of big representative samples of individual cases, on a particular variable of interest, for instance the time-on-task 10-year-olds devote to math assignments. Differences within people can be studied by following individuals over time, for instance by frequently observing the frequency of interactions that a particular child as with the teacher while solving his or her math assignment over an entire school year or more, or by observing changes in the levels of scientific reasoning during a single science activity with a young child (Steenbeek, Jansen \& Van Geert, 2012; van der Steen, Steenbeek, van Dijk \& van Geert, 2014). Collecting information about intra-individual (co-)variability is labor-intensive both for the researcher and the respondent, and it concerns only a single individual or just a few individuals, resulting in samples with dubious representativeness. Hence, it seems highly appropriate to choose for the inter-individual source of (co-)variation, as the major source of information. However, this reasoning is based on the tacit assumption that the nature of the causes governing (co-)variation as it occurs between individuals is the same as the nature of the causes governing (co-)variation occurring within individuals, i.e. variation and covariation over time. In the behavioral and educational sciences, this assumption is mostly incorrect (Molenaar \& Campbell, 2009; Hamaker, 2011; the assumption is called the ergodicity assumption).

The great majority of models based on inter-individual variation describe associations between variables distributed across individuals in the form of correlations, or other forms of regressions, and properties are mostly defined by the additive effects of a great many of independent variables. However, educational processes take place in the form of continuous interactions between various kinds of components. For instance, the effect of an instruction is far from independent on the level and nature of what the instruction intends to change, such as a particular child's understanding of a math strategy or subtraction skill. The contents of instruction are strongly determined on the basis of what the recipients of that instruction students for instance - already know or master (Van Geert \& Steenbeek, 2005). More precisely, instruction itself is a highly adaptive process, and its contents and forms change in relation with in the effects the instruction has on the actual "recipients" such as students receiving a particular instruction see for instance the research on the dynamics of child directed speech, in which the speech patterns of the mother dynamically adapt to the 
linguistic progress made by the child; Van Dijk et al., 2013). That is, whereas the models based on inter-individual variability suggest independent, additive causes, which can be mathematically expressed in the form of simple additions, the model of intra-individual variability suggests dependent, interactive and reciprocal causes, which can be mathematically expressed in the form of dynamic systems, that is, of coupled, iterative equations expressing multiplicative relationships ${ }^{7}$.

In summary, the pattern of inter-individual variability, for instance in data sets representing the association between working memory and math performance in school is quite different from the pattern of intra-individual variability. Within individuals, fluctuations typically show asymmetrical distributions, local peaks and changes in the variability and so forth (Van Geert \& Van Dijk, 2002; Van Dijk \& Van Geert, 2007; Bassano \& Van Geert, 2007; see Kello et al, 2010 for a general discussion, Wijnants et al., 2012 in the context of dyslexia and reading, den Hartigh et al., 2014 with regard to sports performance, de Ruiter-Wilcox, Cox, Kunnen \& van Geert, submitted, in the context of adolescent-parent discussions).

The reason why intra- and inter-individual variability are in fact very different, is that intra-individual variability results from the working of complex dynamic systems - such as an individual person in interaction with a particular educational environment - whereas inter-individual variability typically results from statistically constructed, simple additive systems.

How does this issue of intra-versus inter-individual variability apply to the different communities we introduced earlier? In fact, it will be easy to see that on the level of policymaking, especially on high levels of effect aggregation such as national education programs, it is primarily inter-individual variability that matters. For the policy maker, the intricacies of the idiosyncratic teacher-student interactions and processes are not particularly relevant. What matters is whether on the level of populations, the odds are in favor or not of a particular educational intervention, which is a matter of differences in averages. Think for instance about the average difference in bullying events between groups that have followed a particular educational intervention program to reduce bullying in comparison with groups who have received care-as-usual.

However, for the community of educators, the major problem is that of the control of real-time processes of interaction with their students, taking place in the form of iterative and reciprocal influences. What the educational practitioner primarily uses is a simplex system that helps him understand change in real-time (short-term timescale) and on the long-term timescale, and of the control of such change (how students are reacting in the class, how they progress over the year with ups and downs, etc.). For the educational practitioner, the interindividual differences that emerge are the result of individual, iterative processes, that is to say processes repeated and re-enacted day after day, month after month, showing considerable fluctuations in the variability. The main point here is that, in order to guide the processes of understanding and accomplishment, the educational practitioner needs models grounded in information about the intra-individual variability that is typical of his profession, namely the variability and fluctuations that take place within lessons and across lessons (Steenbeek, Jansen \& Van Geert, 2012). However, the educational research literature

\footnotetext{
${ }^{7}$ Dynamic models, based on intra-individual variability, measured with sufficient frequency and across a sufficient number of subjects, might predict patterns of inter-individual variability, but not the other way around (Steenbeek \& van Geert, 2007).
} 
abounds with pseudo-process models, that is, models of change across time based on information about inter-individual variability. This would be no problem if the information from sources of inter- and intra-individual variability were basically similar, but there is no reason to believe that is indeed so. In summary, to help educational practitioners understand and control educational processes, research should focus much more on individual, real-time trajectories.

\section{The standard model of causality and control}

For an educational researcher, doing research often implies getting directly involved in the praxis of the community of professional practitioners in education, including the practitioners' concerns, evaluations and emotions. For instance, a researcher may want to investigate the effectiveness of a particular intervention, namely a professionalization or coaching program for teachers (Wetzels, Steenbeek \& Van Geert, submitted). This means that the researcher actively interferes in a specific professional practice, in concrete contexts and with concrete people, who experience the research as just one small part of the complex professional praxis they seek to manage. For them, the research is just one of the many elements of daily professional life they must seek to control and bring in accordance with their personal and professional concerns, evaluations and tools. That is to say, their concern is primarily one of educational achievement, which primarily involves the control of the short- and long-term scholarly behavior of their students. For the researcher, the primary concern is one of finding a preferably positive effect of the intervention, that is, of statistically controlling the researcher's variable of choice, such as a particular form of school performance, by a particular form of intervention, e.g. one that regards teacher professionalization.

The notion of achievement implies the notion of causality: it implies that the actions that we perform with the intention to achieve something actually cause that thing to change in accordance with our intentions or goals (for an excellent discussion in the context of education, see Koopmans, 2014). For an educational practitioner, causality is basically the directly observable effect of the practitioner's educational activities on activities and performance criteria in the students, including a host of other criteria such as the social and emotional climate in the class. For the researcher, the notion of achievement via a particular evidence-based intervention, the effectiveness of which is investigated by this researcher, implies a specific view of causality, in which the intervention can be treated as an isolated causal factor, the causal effect of which is entirely due to the factor itself (i.e., the intervention given). The researcher is most likely aware of a variety of factors that also affect the observed result of this causal factor, but the researcher is likely to treat these factors as basically "uncontrolled variables", that is, as random variation that can be reduced to the statistical problem of parceling out the statistical sources of the variance.

From an explanatory point of view, for the researcher, the problem of achievement is likely to be transformed into a particular problem of control of variables. For instance, how can the researcher "control" for the influence of gender (male versus female teachers, male versus female students)), socioeconomic status, school culture and so forth? If the researcher follows the standard practice of research, all these variables are likely to be conceived of as statistically controllable variables. Control is exerted by composing a sufficiently large sample of individual cases (individual teachers in their schools), which allows the researcher to reduce the problem to a problem of explained variance. The variance will be defined by 
differences between the cases in the sample, i.e., between the individual teachers or individual schools. "Explain" will be defined by covariation, that is to say, by the degree to which differences between individuals in the sample with regard to a particular variable of interest - for instance using a particular pedagogical approach, achieving a particular learning result in the students - co-vary with differences in a variable that the researcher believes he or she is controlling. For instance, the researcher sees him- or herself as controlling a particular professionalization intervention, the causal effect of which this researcher is investigating. What researchers wish to find is a statistically significant association - that is to say an association that is unlikely to be due to chance - between the dependent variable, and an independent one that is believed to be under their control (effective control as in the case of an intervention, or statistical control as in the case of an independent variable they wish to associate with a dependent one such as school results).

For educational researchers, this association not only counts as proof of causality, but also as a model of the causal effect of the manipulated variable onto the dependent one. That is to say, the effect which took the form of differences between group averages is likely to be seen as an intrinsic property of the manipulated variable. For instance, if the manipulated variable is a particular intervention (with a control group receiving care-as-usual), the difference between the group averages is seen as a direct expression of a causal "force" inherent in the intervention. The standard reasoning goes on by assuming that, if the effect force lies in the intervention itself, the effect applies to every single individual in the sample or group. Of course, the real, observed effect is a combination of the intrinsic effect of the intervention and the effects of a number of uncontrolled variables that apply to a particular individual. In short, the causal model underlying most of the educational research on interventions is that of a single causal factor - the intervention - having a direct effect on an individual, e.g.. a teacher or a student. In the preceding section, however, we have seen that the processes in which students and teachers are involved are complex networks of mutual causal influences, operating in an iterative and idiosyncratic fashion. In such networks of influences, characterized by intra-individual variability, the effect of a single variable cannot be meaningfully separated from others (see also the discussion on ergodicity and the difference between models based on intra- versus inter-individual variability). Viewed from this perspective, there exists a typical tension between the causal model of the researcher on the one hand, and the nature of the mutual and iterative causal processes in which educators - and students - are involved.

\section{Dynamic systems and investigating and understanding educational processes}

Applying the framework of complex dynamic systems and complexity to education is one (very important) thing, empirically investigating education from that perspective and building specific models and theories is another thing. We have claimed that communities of agents in education - educators, researchers, policymakers - create their own simplex systems, i.e., concerns, goals, tools, concepts, values, practices and so forth, in order to make understanding and achievement possible in the epistemically complex universe of education. As these communities are also in interaction with one another, their simplex systems become entangled with one another, without ever becoming unified.

The scientific researcher in the field of education possesses various tools to contribute to simplifying the epistemic complexity of education, and to help construct the simplex systems of the communities of practitioners and policymakers. To begin with, the general theory of 
complex dynamic systems is a theoretical simplex system that provides a very powerful conceptual framework for reducing the epistemic complexity of education, while retaining the focus on the properties that make education a complex system in a variety of ways. The notion of networks of interacting components, creating dynamic interchanges leading to selforganization and emergence is an important conceptual starting point, inspiring theory formation, empirical research and application.

To begin with, we can use dynamic model building to create simulation environments in which we can study the consequences of the conceptual models that have been suggested to explain important educational phenomena (Van Geert, 2014). For instance, in our own research, we have built conceptual models of scaffolding, which typically involves reciprocal effects of teaching and learning (Van Geert \& Steenbeek, 2005). In addition, research should explicitly focus on individual trajectories of learning and teaching, observed in naturalistic contexts and with a high observation frequency (examples from our lab are van der Steen, Steenbeek, Van Dijk \& Van Geert, 2014; Meindertsma, van Dijk, Steenbeek \& Van Geert, 2014; Kupers, Van Dijk \& Van Geert, 2014; Veenstra, van der Meulen \& van Geert, 2012; and Steenbeek, Jansen \& Van Geert, 2012; Van Dijk et al., 2013). Another line of research that is now becoming increasingly important focuses on the statistical structure of patterns of intraindividual variability, and to use such patterns to discover general properties of the underlying complex dynamic systems from which his variability originates (e.g., the cognitive and perceptual system of a beginning reader; Wijnants et al., 2014). Yet another line of research is to apply predictions based on very general system descriptions, for instance those provided by what was traditionally called catastrophe theory, to observations made in educational systems for instance (e.g., Stamovlasis, 2006). This research focuses on the occurrence of discontinuities in various kinds of educational processes, since discontinuities are typical phenomena occurring in a complex dynamic system such as education.

In the end, what educational research should accomplish is to make a contribution to simplex systems that make the epistemically complex system of education tractable, understandable and manageable for the various communities involved in the process of education. Secondly, it is important to reduce potential tensions, by changing the communication within and between those communities in ways that does justice to the fact that education is indeed epistemically complex, but that it is complex in a way that allows for the emergence of simplex systems through which it may determine its future developments.

\section{References}

Bassano, D., \& Van Geert, P. (2007). Modeling continuity and discontinuity in utterance length: a quantitative approach to changes, transitions and intra-individual variability in early grammatical development. Developmental Science,10(5), 588-612.

Berthoz, A. (2012). Simplexity: simplifying principles for a complex world. New Haven (Ct): Yale University Press.

Bronfenbrenner, U. \& Morris, P.a. (2006). The bioecology model of human development. In W. Damon \& R. M. Lerner (Series Eds.), R. M. Lerner (Vol. Ed.), Handbook of child psychology, vol. 1: Theoretical models of human development (6th ed. , pp. 783-828). New York, Wiley.

Davis, B., \& Sumara, D. (2006). Complexity and education: Inquiries into learning, teaching, and research, Mahwah, NJ: Lawrence Erlbaum, 202 pages. ISBN: \#0-8058-5934-9

de Ruiter-Wilcox, N.M.P., Cox, R.F.A., Kunnen E.S. \& van Geert, P.L.C. (submitted). Mapping the Dynamics of Self-esteem in Real-time.

Den Hartigh, R. J., Gernigon, C., Van Yperen, N. W., Marin, L., \& Van Geert, P. L. (2014). How Psychological and Behavioral Team States Change during Positive and Negative Momentum. PloS 
one, 9(5), e97887.

Frenken, K. (2006). Innovation, evolution and complexity theory. Cheltenham (UK)/Northampton (USA): Edward Elgar Publishing.

Goldspink, C. (2007a). Rethinking educational reform: A loosely coupled and complex systems perspective. Educational Management Administration $\mathcal{E}$ Leadership, 35(1), 27-50.

Goldspink, Ch. (2007b). Transforming education: Evidential support for a complex systems approach E:CO, $9(1-2), 77-92$.

Hamaker, E.L. (2012). Why researchers should think "within-person": A paradigmatic rationale. In M.R. Mehl \& T.S. Conner (Eds.), Handbook of Methods for Studying Daily Life (pp. 43-61). New York, NY: Guilford Publications.

Jörg, T (2011) New Thinking in Complexity for the Social Sciences and Humanities: A Generative, Transdisciplinary Approach. New York: Springer.

Jőrg, T, Davis, B. \& Nickmans, G. (2007). Towards a new, complexity science of learning and education. Educational Research Review, 2, 145-156.

Kello, C. T., Brown, G. D. a, Ferrer-I-Cancho, R., Holden, J. G., Linkenkaer-Hansen, K., Rhodes, T., \& Van Orden, G. C. (2010). Scaling laws in cognitive sciences. Trends in Cognitive Sciences, 14(5), 223-32.

Kluger, J. (2008). Simplexity: why simple things become complex (and how complex things can be made simple). New York: Hyperion.

Koopmans, M. (2014). Change, Self-organization and the Search for Causality in Educational Research and Practice. Complicity: An International Journal of Complexity and Education, 11(1).

Koopmans, M. (2014). Nonlinar change and the Black Box Problem in educational Research. Nonlinar Dynamics, Psychology, and Life Sciences, (1), 5-22

Koretz, D. (2008). Measuring up. Cambridge: Harvard University Press.

Küpers, E., van Dijk, M., McPherson, G. \& van Geert, P. (2014). A dynamic model that links skill acquisition with self-determination in instrumental music lessons. Musicae Scientiae, 18(1), 17-34.,

Meindertsma, H. B., van Dijk, M. W., Steenbeek, H. W., \& van Geert, P. L. (2014). Assessment of Preschooler's Scientific Reasoning in Adult-Child Interactions: What Is the Optimal Context? Research in Science Education,44(2), 215-237.

Molenaar, P. C. M., \& Campbell, C. G. (2009). The new person-specific paradigm in psychology. Current Directions in Psychological Science, 18(2), 112-117.

Stamovlasis, D. (2006). The nonlinear dynamical hypothesis in science education problem solving: a catastrophe theory approach. Nonlinear dynamics, psychology, and life sciences, 10(1), 37-70.

Steenbeek, H., Jansen, L., \& van Geert, P. (2012). Scaffolding dynamics and the emergence of problematic learning trajectories. Learning and Individual Differences, 22(1), 64-75.

Steenbeek, H.W. \& van Geert, P. (2006). A Theory and Dynamic Model of Dyadic Interaction: Concerns, Appraisals and Contagiousness in A Developmental Context. Developmental Review, 27, 1- 40.

Steenbeek, H.W. \& van Geert, P.L.C (2008). An Empirical Validation Of A Dynamic Systems Model Of Interaction: Do Children Of Different Sociometric Statuses Differ In Their Dyadic Play? Developmental Science, 11(2), 253-181.

Steenbeek, H., \& van Geert, P. (2013). The emergence of learning-teaching trajectories in education: a complex dynamic systems approach. Nonlinear dynamics, psychology, and life sciences, 17(2), 233-267.

Steenbeek, H. W. \& Van Geert, P.L.C. (forthcoming). Assessing young children's learning and behavior in the classroom; a complexity approach. In International Handbook on Early Childhood Education, International Editors: Marilyn Fleer and Bert van Oers, Volume 2 -Curriculum and assessment, volume editor G.M. van der Aalsvoort

Van Der Steen, S., Steenbeek, H., Van Dijk, M., \& Van Geert, P. (2014). A process approach to children's understanding of scientific concepts: A longitudinal case study. Learning and Individual Differences, 30, 84-91.

Van Dijk, M. \& Van Geert, P. (2007). Wobbles, humps and sudden jumps: A case study of Continuity, discontinuity, and variability in early language development. Infant and Child Development, 16, 7-33.

Van Dijk, M.; van Geert, P.; Korecky-Kroell, K.; Maillochon, I.; Laaha,; S. Dressler W.U. \& Bassano, D. (2013). Adaptation between child directed speech and early child language; a developmental perspective. Language Learning, 63, 243-270. 
Van Dijk, M.W.G. \& Van Geert, P.L.C. (to appear). The nature and meaning of intra-individual variability in development in the early life span. In M. Diehl, K. Hooker \& Sliwinski, M.(Eds.), The Handbook of Intraindividual Variability across the Life Span. New York: Taylor \& Francis.

van Geert, P. (1991). A dynamic systems model of cognitive and language growth. Psychological Review, 98, 3-53.

Van Geert, P. (1994). Dynamic systems of development: Change between complexity and chaos. New York: Harvester Wheatsheaf.

Van Geert, P. (2014). Dynamic Modeling for Development and Education: From Concepts to Numbers. Mind, Brain, and Education, 8(2), 57-73.

Van Geert, P., \& van Dijk, M. (2002). Focus on variability: New tools to study intra-individual variability in developmental data. Infant Behavior and Development, 25, 340-375.

van Geert, P., \& Steenbeek, H. (2005). The dynamics of scaffolding. New Ideas in Psychology, 23(3), 115-128.

Veenstra, B., van Geert, P. L., \& van der Meulen, B. F. (2012). Distinguishing and Improving Mouse Behavior With Educational Computer Games in Young Children With Autistic Spectrum Disorder or Attention Deficit/Hyperactivity Disorder: An Executive Function-Based Interpretation. Mind, Brain, and Education, 6(1), 27-40.

Weisstein, E.W. (1999). CRC Concise Encyclopedia of Mathematics. Boca Raton-New York: CRC Press

Wetzels, A. F. M., Steenbeek H.W. \& Van Geert, P.L.C. (submitted). A complexity approach to investigating the effectiveness of an intervention for lower grade teachers on teaching science.

Wijnants, M. L., Hasselman, F., Cox, R. F. a, Bosman, a M. T., \& Van Orden, G. (2012). An interactiondominant perspective on reading fluency and dyslexia. Annals of Dyslexia, 62(2), 100-19.

\section{About the Authors}

Paul van Geert holds a doctoral degree from the University of Ghent (Belgium) and is a professor of developmental psychology at the University of Groningen in the Netherlands since 1985. He has had a pioneering role in the application of dynamic systems theory to a broad range of developmental areas, including early language development and second language acquisition; cognitive development in the context of learning-teaching processes; and social development including social interaction and identity. His main aim is to better understand the general nature of developmental dynamics, i.e. nature of the mechanism(s) that drive and shape a developmental process in an individual, as the individual, given his or her biological properties and potentialities interacts with his or her actively explored and transformed environment. He has been Fellow at the Center for Advanced Studies in the Behavioral Sciences and has held visiting professorships at the Unversities of Torino (Italy), Paris V and Reims (France), Trondheim (Norway) and Harvard University (Mind-Brain-Education programme). For his research and an overview of his artwork, see www.paulvangeert.nl

Henderien Steenbeek studied developmental psychology at the University of Groningen, where she defended her $\mathrm{PhD}$ thesis in 2006. The subject of her thesis was modeling dyadic child-peer interactions during play. She currently works as associate professor at the department of Developmental Psychology at the same university. In addition, she works as a professor at Teacher College at the University of Applied Studies in Groningen. In her work she focuses on child-adult and child-child interaction in playeducational settings. Her research themes are: children's learning processes in primary education (with a focus on children with special needs, and excellent performing children), and the dynamics of children's play. Most studies are focused on the observation of interaction behaviors in naturalistic circumstances. http://www.rug.nl/staff/h.w.steenbeek/research

\footnotetext{
(c) Copyright 2014. The authors, Paul van Geert and Henderien Steenbeek, assign to the University of Alberta and other educational and non-profit institutions a non-exclusive license to use this document for personal use and in courses of instruction provided that the article is used in full and this copyright statement is reproduced. The authors also grant a non-exclusive license to the University of Alberta to publish this document in full on the World Wide Web, and for the document to be published on mirrors on the World Wide Web. Any other usage is prohibited without the express permission of the authors.
} 